\title{
Using Slowmation for animated storytelling to represent non-Aboriginal preservice teachers' awareness of "relatedness to country"
}

\author{
Anthony McKnight, Garry Hoban and Wendy Nielsen \\ University of Wollongong
}

\author{
An Outstanding Paper Award recipient, ascilite Sydney 2010 Conference
}

\begin{abstract}
In this study, a group $(\mathrm{N}=15)$ of final year non-Aboriginal preservice teachers participated in an elective subject that aimed to raise their awareness about Aboriginal ways of knowing. A vital aspect of the course was developing the preservice teachers' awareness of "relatedness to country" which is a key belief for Aboriginal people. The non-Aboriginal preservice teachers selected their own special place and then experienced Aboriginal ways of knowing throughout the course and visited local Aboriginal sites to hear and listen to stories shared by an Aboriginal Elder. At the end of the subject, the preservice teachers created their own animated story about their special place using an approach called called Slowmation (abbreviated from "Slow animation"), which is a narrated stop-motion animation that is played slowly at 2 photos/second to tell a story. It is a simplified way for preservice teachers to make animations that integrates aspects of claymation, digital storytelling and object animation. To research this approach, the preservice teachers were interviewed at the beginning and end of the course as well as submitting their animation for assessment. Data collected revealed that all the preservice teachers were able to make an animated story explaining their relationship to their "special place" and most developed a deeper understanding of what a relational approach to country means. Getting the preservice teachers to make animated stories helped them to reflect upon their special place and was a creative way to develop their awareness of cultural diversity, especially about Aboriginal ways of knowing.
\end{abstract}

\section{Background}

In Australia, preservice teachers are usually educated in a four-year degree with subjects that use a Western knowledge system. Increasingly, teacher education courses are introducing subjects into courses to inform preservice teachers about Aboriginal ways of knowing in order to develop an awareness of Aboriginal cultures and practices. Central to these subjects is an awareness of the distinct nature of Aboriginal ways of knowing in terms of Aboriginal paradigms and epistemologies. According to Wilson (2001):

An Aboriginal paradigm comes from the fundamental belief that knowledge is relational. Knowledge is shared with all of creation... It is with the cosmos, it is with the animals, with the plants, with the earth that we share this knowledge. It goes beyond the idea of individual knowledge to the concept of relational knowledge. (p. 176-177) 
Aboriginal epistemologies involve knowing about your place with and on country through developing, maintaining and nourishing respectful relationships in relation to all the connecting entities of creation. For individuals, relatedness and relationships are enhanced through the various 'contemporary' life stages and teachings. These teachings are strongly dependent on the stories told by Elders and so it is important for individuals to develop responsibility for living respectful relationships with country and understanding the holistic nature of "relatedness". Although it is increasingly recognised that preservice teachers should develop an understanding of Aboriginal ways of knowing, it is usually presented didactically through lectures and tutorials in preservice teacher education subjects. To build a deeper sense of relatedness and relationships, it would be useful to develop a subject that uses an experiential approach to enable preservice teachers to experience and feel Aboriginal ways of knowing. In addition, it would be useful to enable preservice teachers to use technology to creatively represent the development of 'new' Aboriginal ways of knowing from their 'old' Western ways of knowing.

\section{Theoretical background}

At the University of Wollongong in the Faculty of Education in 2010, a new fourth year preservice elective subject, Aboriginal Ways of Knowing and Learning, was designed to introduce non-Aboriginal preservice teachers to Aboriginal ways of knowing, particularly through the means of experiencing knowing through storytelling. This approach was utilised because storytelling is a well-established and often-used teaching and learning practice within schools and Aboriginal education. In designing the subject, a conceptual framework for the subject was developed based on a Relational Theory approach which draws upon teachings of Respectful Relationships (Harrison, 2009) and an Aboriginal theory of Relatedness (Martin, 2008). Uncle Max Harrison is a Yuin Elder and Lawman who influenced the first author in his cultural education, which included: "once you take the story from country onto another it loses its sacredness" (personal teachings, 2010). Further, Martin's theory articulates Aboriginal ways of knowing, doing and being succinctly and respectfully for university research and teaching. It is imperative to show respect to Martin and her ancestors in using her theories, as ways of knowing, doing and being are particular to her country and cannot be simply adopted for another place or country. To be respectful to Yuin country and ancestors, Harrison's respectful relationships approach and teachings have been combined with Martin's explicit guide for researchers to re-figure Yuin stories and teachings in academia for the pre-service subject that is the focus of this study.

Experience-based education presents the laying of individuals' openness to knowledge through the agency of the land (Birrell, 2006). According to Birrell, the land holds stories and Aboriginal ways of knowing that involve less emphasis on the intellectualisation of the stories, and rather more emphasis on the emotional feeling and observed nature of the story. Martin's (2008) Relatedness Theory underpins the relational approach that is key to the current research. Martin's methods provide a culturally-appropriate platform for research on our preservice teachers' developing sense of Aboriginal ways of learning, being and doing, a research platform that acknowledges the power relationships within western research approaches. We share Martin's view that through an appropriate research approach, power can be shared respectfully between Aboriginal and non-Aboriginal knowledge systems and the people who negotiate the systems. In Martin's Quandamoopah ontology and First Story 
Worldview, there are seven entities: People, Land, Animals, Plants, Skies, Waterways and Climate: "The term entity is preferred to the term elements because it more strongly acknowledges their essential places and roles within our ontology" (p. 68). The entities are not ranked in any order of importance, as each entity is just as important as the other. In contrast to many western stories, the people or human entity is not the primary focus of Aboriginal stories and all entities are just as important for the 'person' engaging in the story. However, all of the entities' ancestors are the core of the stories that inform and centralise everything for the human learning through the stories.

Most of the theory for the Aboriginal Ways of Knowing and Learning subject and the corresponding research project has been drawn from the stories from country and in showing respect for them, contributes to protecting them from being dismantled by Western hegemonic influences. Showing respect within the subject design and teaching approach was essential for this protection, and it was a major focal point in the first few weeks of the subject that was brought into individual and collective awareness, and then developed, distilled and continually refocused. As Country is the source of Aboriginal knowledge, country was therefore presented at the forefront of the relational approach in guiding the pre-service teachers' experiences in and out of the classroom. Aboriginal knowledge has been described by Mowaljarlai (1993, cited in ABC Radio National Transcripts, 1995), a senior traditional lawman of the Ngarinyin people in the West Kimberley, as 'pattern thinking'. Pattern thinking is a system of relationships that has no bosses, no rules and the relationship comes from the land (ABC Radio National Transcripts, 1995). Henceforth, every natural entity has a pattern and is a part of all the other living patterns that make up creation, and if some thing or one comes to dominate, the pattern of life is disrupted or broken.

In striking contrast to a Western worldview that is outcomes-based, traditional Aboriginal learning of knowledge sought no particular outcomes, judgements or opinions on individuals' learning journey (Edwards \& Buxton, 1998). The journey is the individual's interpretation, experience and/or experimentation in relationship and relatedness to land and its entities through story, dance, art, respect and lore (Harrison, 2008; Martin, 2008; Edwards \& Buxton, 1998) where Aboriginal knowledge lies. Showing respect for Aboriginal stories in their use, exploration and discussion was critical as we provided the preservice teachers a 'hands on' experience of practising what they had learned to that point from earlier work in the previous year's Aboriginal Education core subject that is a mandatory subject and the prerequisite for the elective subject being described here. More specifically, developing further awareness of the hegemonic influences of Western institutions and as individuals reflecting on such processes as assimilation and the power of 'whiteness'. For example, a Dreaming story was shared in order to demonstrate the basic understanding that an adult cannot tell another adult what to do. Through exploring the preservice teachers' experience with country through storytelling, it becomes possible to see how stories set the morals, behaviour and processes that lay the foundation for both the design of the subject and protocols for assessment that lie at the intersection of two conflicting knowledge systems.

To examine the "relational approach to country" as it intertwines purpose, process and outcome for the subject, in particular, relation to country as an Aboriginal way of knowing, being and doing, the pre-service teachers selected their own special place, based on personal experiences, and participated in a 'traditional' Aboriginal cultural education experience, on country, to re-frame their understandings of their own 
special place through Aboriginal ways of knowing. We expected that new understandings of their own relationality to this special place would develop and we sought a means for our preservice teachers to represent the journey of developing their 'new' relationship to their special place. Accordingly, the preservice teachers were expected to create their own narrated animation using a new but simplified way of making an animation, called a 'Slowmation'.

\section{Slowmation: A simplified way of making animated stories}

A "slowmation" (abbreviated from "slow animation") is a narrated stop-motion animation created by preservice teachers that is played slowly at 2 photos/second to tell a story (Hoban, 2005, 2007, 2009). It is a simplified way of creating an animation that engages preservice teachers in telling a story through making a sequence of five connected representations: (i) notes from preparation or experiences; (ii) storyboard to plan the animation; (iii) making simple models; (iv) taking digital still photos of the models as they are moved manually; and (v) constructing the animation. Free examples, instructions and suggestions for implementation can be seen at the project web site http://www.slowmation.com/. In previous studies, slowmation has been used to enable preservice teachers to explain science concepts and this is the first study to use the process for storytelling.

The creation process integrates features of clay animation, object animation and digital storytelling. Similar to clay animation (Witherspoon, Foster, Boddy \& Reynolds, 2004), slowmation uses a stop-motion technique that involves the manipulation of models as digital still photos are taken of each manual movement. However, a slowmation is played at 2 frames/second to explain a story or science concept whereas clay animation is played at 20 frames/second to animate the story. Like object animation, a range of materials that are commonly found in primary classrooms (Laybourne, 1998) can be used, such as plastic models or wooden, paper or cardboard cutout models. Similar to digital storytelling (Lambert, 2002), a key part of creating a slowmation is that a narration and existing photos of animals, plants or objects can be added by learners to explain the story or science concept as the models are animated as in a narrated flip book.

Preservice teachers can learn how to use the approach in a two-hour workshop that will give them enough skills to create their own narrated animation. In sum, a slowmation displays the following features:

- Purpose - the goal of a slowmation is for preservice teachers to make a 1-2 minute animated mini-movie to tell a story, and through the creation process, learn about the story's meaning. The design of the slowmation can include a range of technological enhancements such as narration, music, other photos, diagrams, models, labels, questions, static images, repetitions and characters.

- Timing - slowmations are usually played slowly at 2 frames/second, not the usual animation speed of 20-24 frames/second, and thus need ten times fewer photos than in clay or computer animation, hence the name "Slow Animation" or "Slowmation";

- Orientation - models are made in 3D and / or 2D and usually manipulated in the horizontal plane (on the floor or on a table) and photographed by a digital still 
camera mounted on a tripod looking down or across at the model. This makes the models easier to make, move and photograph;

- Materials - because models do not have to stand up, many different materials can be used such as soft play dough, plasticine, 2D pictures, drawings, written text, existing 3D models, felt, cardboard cut-outs and natural materials such as leaves, rocks or fruit; and,

- Technology - preservice teachers use their own digital still cameras (with photo quality set on low resolution so as to avoid overloading the editing software) or cameras in mobile phones and free movie-making software available on their computers (e.g. iMovie or SAM Animation on a Mac or Windows Movie Maker on a PC).

In summary, slowmation greatly simplifies the process of making an animation whereby preservice teachers use 2D or 3D models that may lie flat on a surface, design the animation to play slowly at 2 frames/second, thus requiring 10 times fewer photos than normal animation, and use their own digital still camera and movie making software on their own computers. The narrated animation produced is a multimodal representation created by the preservice students to explain the story of their own "special place" using perspectives about Aboriginal ways of knowing that they have learned from the elective subject.

\section{Methodology}

\section{The elective subject}

The subject in this study was an elective in the final year of a four year Bachelor of Education for primary teachers at the University of Wollongong. Fifteen preservice teachers were enrolled in the subject and seven of them gave ethics approval to be involved in data collection. The subject immerses itself within Aboriginal Ways of Knowing, the Quality Teaching Framework and Aboriginal peoples' and communities' Ways of Behaving. The supportive subject provided opportunities for students to engage in practical 'hands on' experiences. A major focus of the subject was a field trip to a significant Aboriginal 'place'. Students experienced Aboriginal ways of learning with 'Country' through an Elder. The excursion experience and the subject content assisted the pre-service teachers to engage in and teach Aboriginal perspectives and utilise Aboriginal pedagogies. More importantly the subject helped pre-service teachers in their understanding of and relationship with country and Aboriginal people to ultimately develop skills to enhance the delivery of meaningful Aboriginal educational approaches for all students in schools. A summary of the critical features that underpin the design of the elective subject is shown in Table 1.

\section{Data gathering methods}

At the beginning of the subject, each of the seven preservice teachers were interviewed by a research assistant to ascertain their understanding of Aboriginal ways of knowing with particular regard to a relational approach to country. Typical questions included, What might be your special place be? Why is this place significant to you? How does your special place make you feel? What does 'country' mean to you? What do you understand by the phrase, 'relational approach to country'? The preservice teachers then participated in activities in the subject based on Aboriginal ways of knowing as 
Table 1: Design features of the elective subject

\begin{tabular}{|c|c|}
\hline Feature & Example \\
\hline Introduction & $\begin{array}{l}\text { Preservice teachers were required to introduce themselves in an } \\
\text { Aboriginal way. That is, they needed to say who they are, where they } \\
\text { come from, who is their mob and what they would like to learn. This } \\
\text { process allowed them to find connections and a sense of belonging. }\end{array}$ \\
\hline Pedagogy & $\begin{array}{l}\text { The pedagogy of the subject was based on Aboriginal ways of } \\
\text { knowing whereby the notion of community is important. This was } \\
\text { modelled throughout the subject in terms of sharing, caring, respect } \\
\text { and being an "extended family". }\end{array}$ \\
\hline Special place & $\begin{array}{l}\text { Preservice teachers were asked to think about a place that is special } \\
\text { and significant to them. They were asked to consider why it is special } \\
\text { to them. For instance, the special place may be somewhere they spent a } \\
\text { lot of time, somewhere they have gone to relax, a place where they } \\
\text { have camped with their family, or even somewhere they enjoy going. } \\
\text { In other words, their special place must have some meaning to them. } \\
\text { The special place is integral to this subject and became the focus for } \\
\text { developing a "relational approach to country" and representing this in } \\
\text { an animated story (slowmation) as a final task in the subject. }\end{array}$ \\
\hline $\begin{array}{l}\text { Cultural } \\
\text { excursion }\end{array}$ & $\begin{array}{l}\text { The preservice teachers were taken on a cultural excursion to } \\
\text { Biamanga Mountain on the south coast of NSW where Aboriginal } \\
\text { Elder, Uncle Max Harrison, guided them with some cultural teachings. } \\
\text { A cultural excursion provides preservice teachers with an opportunity } \\
\text { to visit country and experience country as a teacher and individual. } \\
\text { Uncle Max, the local Elder, guided the excursion, which is essential for } \\
\text { the preservice teachers in their experiencing Aboriginal knowledge } \\
\text { and culture in this country. }\end{array}$ \\
\hline $\begin{array}{l}\text { Slowmation } \\
\text { workshop }\end{array}$ & $\begin{array}{l}\text { Halfway during the course, the preservice teachers were led by the } \\
\text { second author in a 2-hour workshop on how to create a slowmation. } \\
\text { During this time they observed some slowmations created by other } \\
\text { preservice teachers, created a simple trial example for themselves and } \\
\text { developed sufficient skill to create their own to tell a story about their } \\
\text { special place. Examples, instructions and resources are available on the } \\
\text { web site http:/ / www.slowmation.com/ }\end{array}$ \\
\hline Lesson plans & $\begin{array}{l}\text { The subject requires preservice teachers to complete lesson plans } \\
\text { whilst they are working on their slowmation animation. This helps } \\
\text { with their hands on understanding of how Aboriginal storytelling } \\
\text { processes can work with standard curriculum. }\end{array}$ \\
\hline Sharing & $\begin{array}{l}\text { Sharing and telling stories is an important part of Aboriginal culture. } \\
\text { An element of the final task of the subject was for preservice teachers } \\
\text { to share their slowmation stories with others at the end of the session. }\end{array}$ \\
\hline
\end{tabular}

well as the 2-hour workshop where they learned to create a slowmation. This was enough for them to create their own as the third assignment in the subject. At the end of the subject, each of the preservice teachers were interviewed again by a research assistant using similar questions and the students' slowmations were collected as artifacts of their learning.

Adding a narrative to a story involves an element of narrative inquiry that further assists the current research project as it provides the notion of authenticity. Connelly and Clandinin (cited in Clandinin, Pusher \& Orr, 2007) describe narrative inquiry: 
The study of experience as story, then, is first and foremost a way of thinking about experience. Narrative inquiry as a methodology entails a view of the phenomenon. To use narrative inquiry methodology is to adopt a particular narrative view of experience as phenomena. (p. 22)

The current study was a project aimed at engaging preservice teachers in Aboriginal ways of knowing. This 'knowing' must be bound to a relational approach, and hence, the preservice teachers' experimentation and exploration of their learning must be respected and related back to stories from country. It is important to emphasise that for many of the preservice teachers, this was their first hands on experience and engagement with Aboriginal ways of learning. As such, for the purposes of this paper, we endeavour to share preservice teachers' pre and post interview statements as well as images from their slowmations in order to demonstrate what the preservice teachers have learnt.

As researchers we have the benefit of a more holistic view on what the preservice teachers have learnt and we acknowledge that standard formats for conference presentations or journal articles limit our ability to present the preservice teachers' learning in a totally respectful way. Our interest in the analysis of the preservice teachers' animations was to see if and how much of country came to the leading position in their stories and if, in their representations, country is protected. In order to honour the preservice teachers' process of coming to know, it was important to not pass judgment or reflect on their story of country. We were concerned as instructors that our reflection may lead toward a fantasy position on their learning. By way of example, this 'fantasy position' arose as the first author fell into the trap of making a judgment on one student's reflection of being on country with Uncle Max:

I was taken away from where I am normally involved in busy activities, taken out on country, taken away from everyone, disconnected, your phone not working... for one minute it made you think about things you would never have thought about and all these other things that I never thought I had in me. (Student 3).

This statement came from the second interview with the student, and it seemed that her reflection represented a very physical perspective on country (e.g. country as geography rather than entity), but after listening to the post-interview in its entirety, it was clear that her statements demonstrated growth in her understanding of country. This alerted us to the need to take care not to judge someone else's relationship with country. This was a balancing act in a way, as the subject aimed to guide preservice teachers through and with the stories, but not through opinion or judgment. There is one instance when judgment is appropriate: to protect country against the influence of 'whiteness' and to guide and maintain individual relatedness and responsibilities. Morton-Robinson (2005) argues the importance of critical whiteness studies to assist in the analysis and production of knowledge with peoples who are perceived to be 'raced' by the dominant culture.

\section{Results}

The two main intentions of the subject, Aboriginal Ways of Learning, were for preservice teachers to develop an understanding of relatedness to country and to apply this way of 'thinking' to their own "special place" through the representation of a slowmation (Hoban, 2005, 2007, 2009). 


\section{Relatedness to country}

In terms of understanding the phrase "relatedness to country", it was clear from the preservice teachers' answers to the question, "What does relatedness to country mean?" that their understanding varied, often reflecting a superficial understanding of the phrase. Several of the preservice teachers had an environmental or geographical interpretation:

How you relate to it as in your feelings at what you regard as what is in your country. (Student 1)

It is my relationship to country, things die and are absorbed back. Everything you do is from country. Whole life is around country, animals, etc. (Student 2)

It is people and our relationship to earth. (Student 3)

I'm not able to answer that question. (Student 4)

I'm just starting to grasp that now. It is an Aboriginal perspective - how I treat the land and country will determine what I will get out of it. Don't treat it well and it won't be there forever. I was not taught this when I was growing up. (Student 5)

I think it's just showing your connectedness and how I suppose in some ways in this busy world you kind of... you lose that connectedness sometimes, and so it's sort of bringing this back. It pulls you back into say well it's that environmental perspective as well, it's like just stopping and taking a look around you and realising what's around you, and reading and listening and stuff like that. (Student 6)

One of the preservice teachers, however, did realise that there is also a spiritual connection that is consistent with Aboriginal ways of knowing about country:

I'm not completely sure but I guess it's just like the connection of everything, the whole country as like... so like the earth can bring spiritual healing and the physical like food. (Student 7)

It appeared from the first interviews that the preservice teachers had little understanding about Aboriginal ways of knowing and relatedness to country, which is not surprising given that most of the preservice teachers in the subject had had very little experience with such ways of knowing. The preservice teachers' change in understandings became clear by the end of the subject during the post-interviews, when they were asked to reflect on their new understandings of relatedness to country. As shown in the following quotations from the interviews, the preservice teachers had developed a deeper understanding of the term that reflected Aboriginal ways of knowing and showed a more holistic sense of being connected:

Developed a deeper understanding, we have a connection to country and I now understand more of that relationship with country. I didn't really think about why before you went to a special place and [the subject] made you think about what you need from that spot. (Student 2)

How you feel within the environment and feelings. Had never thought of things that way before. (Student 4 )

For me it's just that, a sense of belonging I can look around and see the trees and don't see the buildings, as long as I have that attachment through visual, and just that being at peace with yourself and knowing where you are... It's a sense of belonging. (Student 6) 
In particular, several of the preservice teachers mentioned that it included a "spiritual connection":

I didn't understand it at first, it's different for everyone, it's about being grounded, being out there connecting spiritually in your own way. (Student 1 )

Yeah, I think before when I started this subject I thought it was physical connection and like the things you do on country. But now I think it's more about the feelings you get as well the emotional and spiritual connection. I think it is still physical as well but more about the emotional way you feel. (Student 3)

Broader, well, better understanding, a relationship with country. Aboriginal people had a spiritual relationship with the land, [I] actually believe that now, and I feel that. (Student 5)

I understand, not just a physical thing but more how you are connected and how spiritually connected, what it is teaching you and what you are learning. (Student 7)

One of the preservice teachers emphasised that it was the cultural excursion with Aboriginal Elder Uncle Max Harrison whereby listening to his stories was most influential on her thinking:

\footnotetext{
It was awesome, that was an experience. Uncle Max's stories and stuff made you stop and think about country and how it should be used and also made you think about the Aboriginal perspective and like this is my special place and it made you stop and think. [It] should probably place significance to the traditional owners and I wondered how they view this place compared to how I view it and am I doing the right thing (Student 7).
}

This student's growing awareness of country, and importantly, her own learning through the indirectness of the relational approach helps to demonstrate the connection Aboriginal peoples have to place. Student 7 figured out for herself that Aboriginal people also have a relationship to the place that this student designated as special. It could be interpreted that this message of Aboriginal peoples' belonging to country has now been felt and not just intellectualised.

\section{Role of the slowmation}

The purpose of getting the preservice teachers to create a narrated animation such as a slowmation was to help them to reflect, think and feel about their special place. During the subject the preservice teachers completed a two-hour workshop on how to make a slowmation that then provided them with the necessary skills to make their own. Most of the preservice teachers took between 5 and 10 hours to make their own slowmation as a way of representing their personal journey through the subject.

In constructing their animations many of the preservice teachers took digital still photos of their special place and then inserted themselves into the story with plasticine models, cutout photographs or small models which they animated using the stopmotion technique. Hence the structure of the animations included digital still photos of the special place that were interspersed with animated cutouts or plasticine models and constructed backdrops. Similar to digital storytelling, a key part of the slowmation is the narration to tell the story of how individuals relate to their special place. One of the preservice teachers explained the role of the narration and the structure of the story: 
The narration I have written focused on how country can help you. The person in my story had a bad experience at school and felt the need to go to her special place in order to think and clear her head. The message I was trying to portray here is that Country is more than just nature, it is an entity present in all our lives that can communicate with us to reconcile issues we may be having. (Student 4)

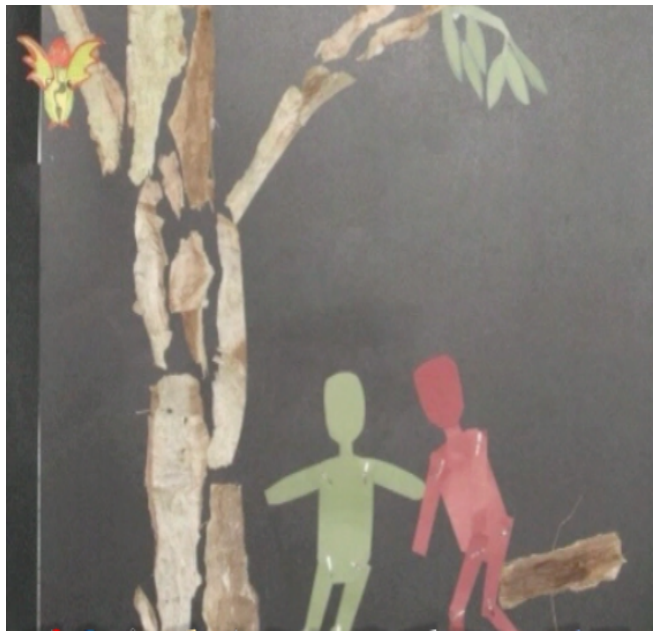

1. A slowmation segment identifies the human and spiritual element of the animation. The left-hand spiritual self cutout leaving the human cutout to sit up high in the tree.

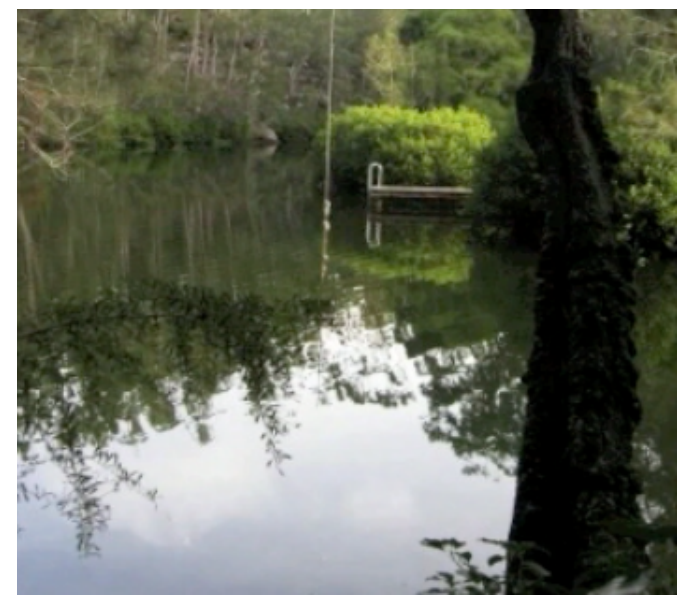

3. A time of reflection on their journey which was explained in the narration.



2. The slowmation then changes to still photographs to demonstrate the journey of the person and their spirit through country.

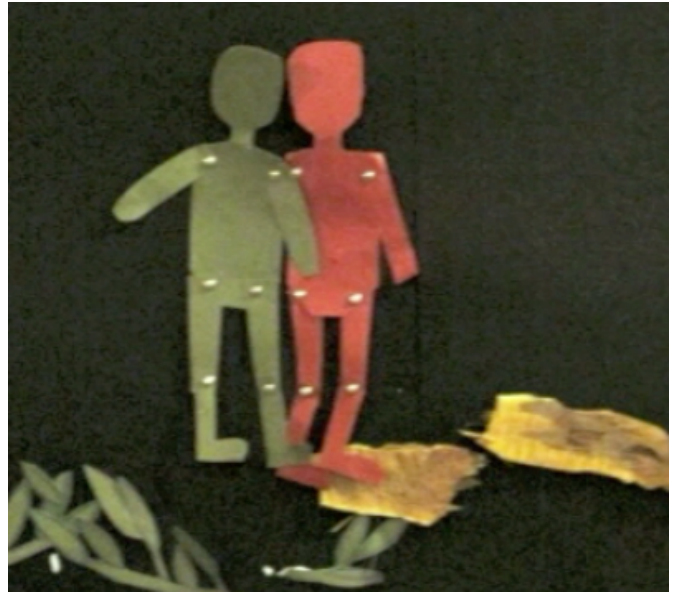

4. This slowmation finishes with the spirit reuniting with the person and walking out of country.

Figure 1: Selection of photos from a slowmation

Figure 1 shows several screen shots from the animation made by Student 4 to demonstrate the diversity of technology and her approach in sharing what she has learnt. It shows how her slowmation integrated the use of digital still photos of her special place with animated cutouts where she placed herself in the story. So the 
digital still photos showed the physical layout of the place and the animated characters showed how the place influenced her feelings and ways of knowing. It was the narration that linked the digital still photos with the animated sections and told the story of her self-awareness, the importance of special places, the connection between the spiritual and physical self, and relatedness to country.

In regard to the use of slowmation to help the preservice teachers represent their relationship to country, the preservice teachers often stated that the creation process helped them to think about and reflect upon their new-found knowledge because the slowmation was a representation with a narration to explain their journey and understandings to someone else:

Slowmation helps you show your story, unique and individual. (Student 1)

The slowmation helped me look at it more carefully and look at different angles, spirituality and how country talks to us and try and represent that in an animation. (Student 2)

Through the relational approach and slowmation you've got to interpret yourself, there was no right or wrong answer; it is your own personal view. I'm telling you about my special place: I'm telling it to get across my point of view. It made you think about how you would tell someone else about it. How would you get across all the emotions and it was hard. It was a good way of telling someone about it who was not there on so many levels. (Student 3)

The slowmation merged all the different methods together. I wanted to show it's not so much what you said or what you do but it's all of that together at the same time. I did not do a narrative, did a nature track...it was hands-on instead of an essay and I learnt more that way. (Student 4)

At first the slowmation concept didn't suit the subject, but now I don't really believe that, it did work... (Student 5)

My link was with the appreciation of using artwork symbols and having my connection through that and the story telling in which I became aware of after the experience (Student 6)

Actually physically going to the place, had story in my head but [the slowmation] made me think about it more...I would like to use it in the classroom (Student 7).

\section{Discussion and conclusion}

A key value of any teacher education program should be the fostering of an appreciation for cultural diversity and different ways of knowing. Awareness of Australia's own Aboriginal ways of knowing should be central to this appreciation. Although this value is relatively common amongst teacher education programs, how to develop this amongst teacher education preservice teachers so that they appreciate and understand these perspectives is more challenging. More often than not, a telling or lecturing approach is used in various subjects. Instead, we used a relational knowledge approach (Harrison, 2009; Martin, 2008) in the elective Aboriginal Ways of Knowing and Learning that focused on preservice teachers experiencing Aboriginal ways of knowing and applying these ways of thinking and knowing to their own chosen special place. Importantly, the students needed to choose a place that already had a special meaning to them (e.g. a quiet place to reflect, favourite beach, camping spot or 
park), but the subject should help them to deepen this meaning. A key part of helping the preservice teachers to reflect upon and represent their newfound understandings was to get them to construct an animated story (slowmation) created as a representation of these understandings.

The Aboriginal epistemology that is foundational to this approach was the dynamic factor that provided guidance for the students on their learning journey in this elective subject. However, the technology and processes of slowmation played an important role in helping the students to look deeper into aspects of the exploration of their special place. In some cases it created an opportunity to engage deeply in the examination of their representations, to clarify the feelings and meanings attached to the slowmation. Furthermore, developing a narrated animation enabled the preservice teachers to make a public display, and in this way share their journey with their peers. The preservice teachers indicated that the slowmation technology was very user friendly and a number of preservice teachers who held some trepidation about the slowmation at the start of the subject had their fears swiftly alleviated through engagement with the user friendly slowmation technology. Most preservice teachers signalled their intention to use slowmation as a classroom teaching technology during their Professional Experience (final internship) and when they start their careers, as slowmation is a very engaging process that can be used with a range of subjects and issues across the curriculum.

All of the preservice teachers made it clear that they valued the two-day excursion with the Aboriginal Elder, Uncle Max Harrison, as an essential element of the subject. Uncle Max's teachings made the biggest impact and really helped the preservice teachers understand Aboriginal connections to country, story telling and a relational approach. The preservice teachers found the subject, content, approach and the slowmation very enjoyable, relaxed, personable and flexible. The preservice teachers now understand why the lecturers could not be very specific at the start of the subject in giving a predetermined framework for the nature of their special place. It was left open for preservice teachers to explore what they know and have learnt, and not have the lecturer over-prescribe the intended outcomes. Process and outcome were one and the same and it was the preservice teachers' developing relationship with country that informed and provided the framework for their stories about their special place.

The preservice teachers' slowmations presented at the end of the subject were excellent, respectful and clearly displayed their emotional and spiritual connections to their special places. The preservice teachers even wanted to make a group slowmation in the last class of the elective. The preservice teachers' grasp of the technology also enhanced and emphasised the depth of their connections to their special places. The representations used in the slowmations varied greatly and reflected the preservice teachers' personalities alongside the nuances of the special places. In particular, narrations varied from music to in depth narratives, and the slowmation process catered for individual experimentation, experiences and explorations. Hence, the preservice teachers' understandings of cultural overlaps and the layering of experience were demonstrated through the use of the technology. This is a good example of having pedagogy drive the use of the technology, not vice versa. The slowmations enabled the preservice teachers to show their insights on relatedness and respectful relationships and exhibited what they had learnt so far in their learning journeys within Aboriginal Ways of Knowing. We hope to further explore the approach used in this subject, linking learning about Aboriginal ways of knowing through experience 
and the use of student-created animations (slowmations), as a way to foster engagement with country and the appreciation of cultural diversity and Aboriginal ways of knowing, being and doing.

\section{Acknowledgments}

1. The project team would like to pay our respects to country and Uncle Max Harrison and his teachings that were fundamental to the subject and the preservice teachers' learning journeys.

2. We would also like to acknowledge and pay our respects to Yuin country. Yuin land provided the gift of knowledge through the sharing of its stories.

3. We would like to also thank and pay our respects to the varying countries that have offered the gifts of special places for our preservice teachers. It is through our preservice teachers' sharing that these gifts have been revealed.

4. Four video modules developed for this approach can been seen at http: / / www.slowmation.com/ and click on Storytelling Using an Aboriginal Perspective. The authors would like to thank Universities Australia for funding these modules from a Cultural Competencies Grant.

\section{References}

ABC Radio National Transcripts (1995). The Law Report: Aboriginal law. 31 October. http: / / www.abc.net.au/rn/talks / 8.30/lawrpt/lstories/lr311001.htm (viewed 14 Apr 2009, verified 14 Jan 2010)

Birrell, C. L. (2006.) Meeting country: Deep engagement with place and Aboriginal culture. Unpublished PhD thesis, University of Western Sydney, College of Arts, School of Education. Australasian Digital Thesis Program, University of Western Sydney. http: / / handle.uws.edu.au:8081/1959.7/20459

Clandinin, J., Pusher, D. \& Orr, A. M. (2007). Navigating sites for narrative inquiry. Journal of Teacher Education, 58(1), 21-35.

Edwards, O. \& Buxton, L. (1998). Guyunggu: An Aboriginal way of being. Catholic Schools Office, Diocese of Broken Bay, Waitara, NSW.

Harrison, M. (2010). Personal teachings, 20 March.

Harrison, M. (2009). My people's dreaming: An Aboriginal elder speaks on life, land, spirit and forgiveness. Sydney: Finch.

Hoban, G. (2005). From claymation to slowmation: A teaching procedure to develop students' science understandings. Teaching Science: Australian Science Teachers' Journal, 51(2), 26-30.

Hoban, G. (2007). Using slowmation to engage preservice elementary teachers in understanding science content knowledge. Contemporary Issues in Technology and Teacher Education, 7(2), 1-9. http: / / www.citejournal.org/vol7/ iss2/general/ article2.cfm

Hoban, G. (2009). Facilitating learner-generated animations with slowmation. In L. Lockyer, S. Bennett, S. Aghostino \& B. Harper (Eds.), Handbook of research on learning design and learning objects: Issues, applications, and technologies (pp. 313-330). Hershey, PA: IGI Global.

Lambert, J. (2002). Digital storytelling: Capturing lives, creating community. Berkeley, CA: Digital Diner Express. 
Laybourne, K. (1998). The animation book. New York: Three Rivers.

Martin, K. (2008). Please knock before you enter: Aboriginal regulation of outsiders and the implications for researchers. Teneriffe, QLD: Post Pressed.

Morton-Robinson, A. (2005). Whiteness matters: Australian studies and Indigenous studies. In D. Carter, K. Darian-Smith \& G. Worby (Eds.), Thinking Australian studies teaching across cultures. University of Queensland Press, Australia, pp. 136-146. http: / / eprints.qut.edu.au/28295/

Wilson, S. (2001). What is an Aboriginal research methodology? Canadian Journal of Native Education, 25(2), 175-179.

Witherspoon, T. L, Foster, M. S., Boddy, G. \& Reynolds, K. V. (2004). Clay animation: Encouraging visual literacy. Paper presented at the World Conference on Educational Multimedia, Hypermedia and Telecommunications, Lausanne Switzerland.

Yunkaporta, T. \& McGinty, S. (2009). Reclaiming Aboriginal knowledge at the cultural interface. The Australian Educational Researcher, 36(2), 55-72.

http:/ / www.aare.edu.au/aer/online/0902/0902_d.pdf

This article received an Outstanding Paper Award at ascilite Sydney 2010, gaining the additional recognition of republication in AJET (with minor changes). The reference for the Conference version is:

McKnight, A., Hoban, G. \& Nielsen, W. (2010). Animated storytelling about "My Special Place" to represent non-Aboriginal preservice teachers' awareness of "relatedness to country". In Curriculum, technology E transformation for an unknown future. Proceedings ascilite Sydney 2010. http: / / www.ascilite.org.au/ conferences/ sydney $10 /$ Ascilite $\% 20$ conference $\% 20$ proceedings $\% 202010 /$ Mcknight-full.pdf

Authors: Anthony McKnight (contact author), Faculty of Education, University of Wollongong, Wollongong NSW 2522, Australia. Email: anthonym@uow.edu.au Web: http://www.uow.edu.au/educ/

Garry Hoban, Faculty of Education, University of Wollongong, Wollongong NSW 2522, Australia. Email: garry_hoban@uow.edu.au Web: http: / / www.uow.edu.au/educ/

Wendy Nielsen, Faculty of Education, University of Wollongong, Wollongong NSW 2522, Australia. Email: wnielsen@uow.edu.au Web: http: / / www.uow.edu.au/educ/

Please cite as: McKnight, A., Hoban, G. \& Nielsen, W. (2011). Using Slowmation for animated storytelling to represent non-Aboriginal preservice teachers' awareness of "relatedness to country". Australasian Journal of Educational Technology, 27(1), 41-54. http: / / www.ascilite.org.au/ajet/ajet27 / mcknight.html 